(C) 2004 American Chemical Society, Chem. Res. Toxicol., Richter tx034210b Supporting Info Page 1

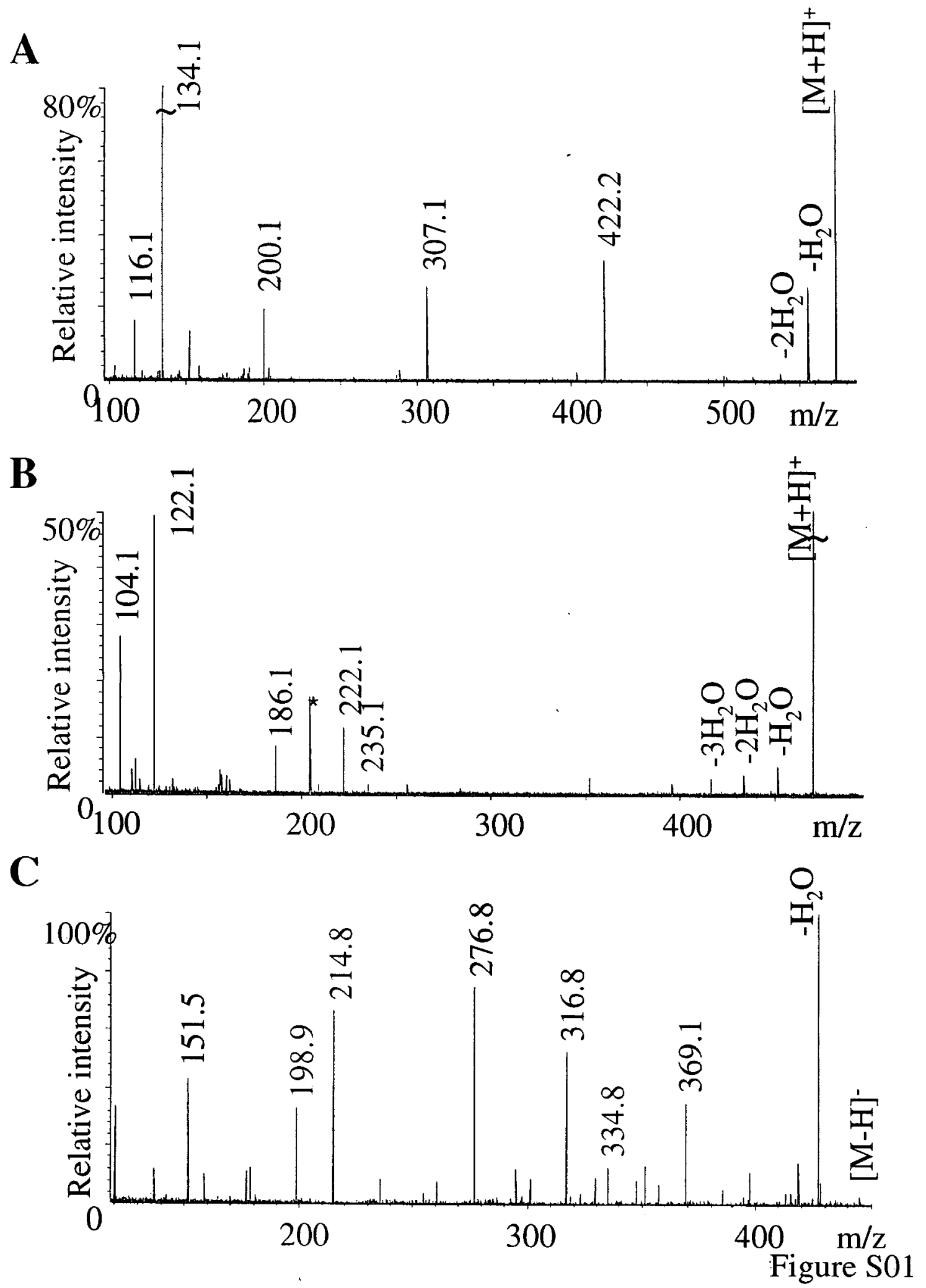


(C) 2004 American Chemical Society, Chem. Res. Toxicol., Richter tx034210b Supporting Info Page 2<smiles>OCC(O)C1(C2(O)CO2)CO1</smiles>

$\underline{\mathbf{a}}$<smiles>OCC(CO)=C(O)C1(O)C=NC(CO)(CO)CO1</smiles><smiles>OC=C(C=CP)C1(O)C=NC(CO)(CO)CO1</smiles><smiles></smiles><smiles>OCC1(CO)COC(O)(CO)C=N1</smiles><smiles>OCC(O)C(O)(CO)C1(O)C=NC(CO)(CO)CO1</smiles>

$\underline{\mathbf{b}}$<smiles>OCC1(CO)COC(O)(C(O)(/C=C\P)CO)C=N1</smiles><smiles>O=C(CP)C(CO)=C1C=NC(CO)(CO)CO1</smiles><smiles>[R]C=CC(C=O)=C1C=NC(CO)(CO)CO1</smiles><smiles>CCC1(C)C2CCC=C(C=O)C2(C)CC[C@@H]1C</smiles><smiles>O/C=C/C1(O)C=NC(CO)(CO)CO1</smiles><smiles>O=C1C(O)OC(CO)C1(O)CNC(CO)(CO)CO</smiles>

Possible precursor ion structures for $[\mathrm{M}+\mathrm{H}]^{+}$ $\mathrm{m} / \mathrm{z} 470.2$<smiles>O=C1C(CNC(CO)(CO)CO)=C(CP)OC1O</smiles><smiles>[TlH]</smiles><smiles>C1CCCCC1</smiles>

Loss of $\mathrm{H}_{2} \mathrm{O}$ $\mathrm{m} / \mathrm{z} 416.2$ (prot. form)

$\mathrm{m} / \mathrm{z} 235.1$ (prot. form)<smiles>O=CC=C1C=NC(CO)(CO)CO1</smiles>

Loss of $\mathrm{H}_{2} \mathrm{O}$, $\mathrm{m} / \mathrm{z} 452.2$ (prot. form)

Loss of $\mathrm{H}_{2} \mathrm{O}$ $\mathrm{m} / \mathrm{z} 434.2$ (prot. form)
$\mathbf{R}$<smiles>CC1CCC2(C)C(C=O)=CCCC2C1(C)C</smiles> 
(C) 2004 American Chemical Society, Chem. Res. Toxicol., Richter tx034210b Supporting Info Page 3<smiles>O=C1C(O)OC(CP)C1(O)COP(=O)(O)O</smiles>

a<smiles>O=C1C(COP(=O)(O)O)=C(CP)OC1O</smiles><smiles>O=C1C(O)OC(CP)C1(CO)OP(=O)(O)O</smiles>

$\underline{\mathbf{b}}$

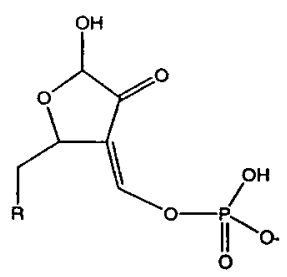

Precursor ion [M-H] $\mathrm{m} / \mathrm{z} 445.2$

Loss of $\mathrm{H}_{2} \mathrm{O}$

$\mathrm{m} / \mathrm{z} 427.1$

$\mathrm{m} / \mathrm{z} 369.1$

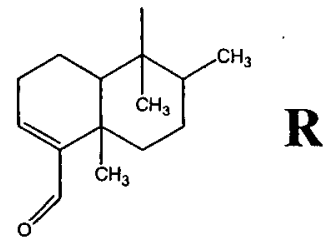

$\mathbf{R}$

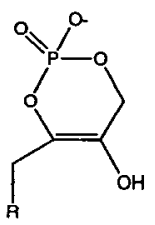

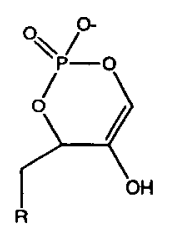

Figure S03 


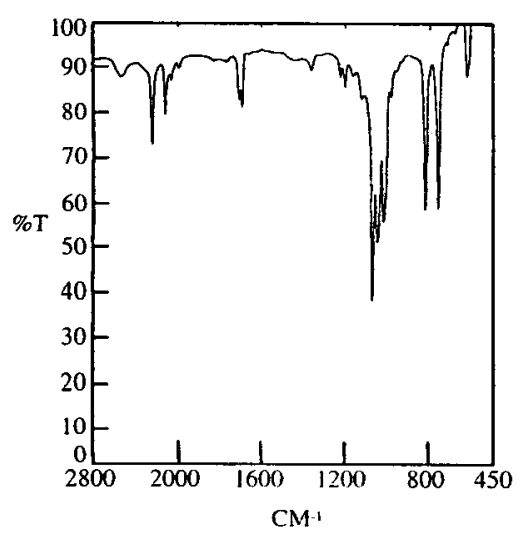

\section{Figure S04}

